Hepatocellular carcinoma (HCC) is the most common liver neoplasm worldwide. Based on its potent inhibition of dihydropyrimidine dehydrogenase (DPD), $\mathrm{S}-1$ is expected to be more active than other fluoropyrimidines against HCC with DPD activity. This systematic review was aimed to as sess the efficacy and safety of S-1 for treatment of advanced HCC.

PubMed, the Cochrane Library, EMBA$\mathrm{SE}$, and ClinicalTrials.gov were searched using the terms "Hepatocellular Carcinoma" or "HCC" or "Hepatoma" or "Liver cancer" and "S-1". Outcomes of main interest included overall survival (OS) and toxicities.

We identified four studies of S-1 treatment alone from 1059 references, including a total of 272 patients. There were two original articles and two conference abstracts. The percentage of male patients ranged from 88 to $91.3 \%$ and median age ranged from 59 to 70 years. Median OS ranged from 8.6 to 16.5 months. The incidences of toxicity of more than $50 \%$ were thrombocytopaenia and fatigue. According to the original description, toxicities were acceptable.

The current evidence from the available clinical studies suggests that S-1 may be an effective and tolerable treatment for advanced HCC. Further clinical studies are warranted to further investigate this treatment option.

Key words: hepatocellular carcinoma, $\mathrm{S}-1$, systematic review.

Contemp Oncol (Pozn) 2017; 21 (1): 16-20 DOI: https://doi.org/10.5114/wo.2017.66653

\section{S-1 for treatment of advanced hepatocellular carcinoma: a systematic review of the literature}

\author{
Wu-kui Huang ${ }^{1 *}$, Li-na You ${ }^{2 *}$, Shu-fa Yang ${ }^{1 *}$, Deng-yao Liư ${ }^{1}$, Mo Liu ${ }^{1}$, \\ Xi-wen Fan ${ }^{1}$
}

'Department of Intervention Radiology, The Affiliated Tumour Hospital of Xinjiang Medical University, Urumqi, Xinjiang, People's Republic of China

2Department of Traditional Chinese Medicine, The Fifth Affiliated Hospital of Xinjiang Medical University, Urumqi, Xinjiang, People's Republic of China

*Contributed equally

\section{Introduction}

Worldwide, hepatocellular carcinoma (HCC) is one of the most usual cancers. HCC ranks sixth regarding prevalence and third regarding mortality among malignant tumours [1]. HCC accounts for $85-90 \%$ of all primary hepatic malignancies [2]. Cirrhosis is a major risk factor for HCC, and $60-80 \%$ of these tumours arise in patients with cirrhosis. The major chronic liver diseases underlying the development of cirrhosis and HCC include chronic viral hepatitis (B and C), non-alcoholic steatohepatitis, and alcoholic liver disease. In the United States, the incidence of HCC has increased from 1.4 cases/100,000 in 1976-1980 to approximately 5 cases/100,000 in 2003-2006 [3, 4]. Most patients diagnosed with HCC are not amenable to curative treatments because of advanced stage according to Barcelona Clinic Liver Cancer (BCLC) criteria.

Systematic chemotherapy has been recognised as a palliative treatment option for patients with advanced HCC [5], such as combination chemotherapy of oxaliplatin and S-1 [6]. Conventional chemotherapy, usually called intravenous chemotherapy, often implicates a pulsatile administration schedule for the treatment of a patient using the maximum tolerated dose of a cytotoxic drug. The prolonged break between two therapy cycles not only allows recovery from all kinds of toxicities, but also provides an opportunity, unluckily, for the drug-treated tumour to recover [7]. On the contrary, metronomic S-1 chemotherapy is performed at frequent intervals using nontoxic or low-toxic dose with no prolonged break. Some studies have confirmed the effect of S-1 for HCC.

To our knowledge, sorafenib is the standard recommendation for advanced HCC. However, because of its adverse effects, modest efficacy, and high cost, the availability of sorafenib is limited [8]. Sorafenib is a self-paying drug in China. It costs $¥ 151,152$ (approximately \$22,931) for each patient. In a developing country, most patients cannot afford this cost. However, S-1 is gratifying in the content of Chinese medical insurance. If S-1 can improve survival, it means that s- 1 is a promising treatment of advanced HCC according to the principle of pharmacoeconomics.

Through the literature retrieval, there is not a systematic review of S-1 for the treatment of HCC. We have conducted a systematic review to assess the efficacy and safety of S-1 for the treatment of advanced HCC.

\section{Material and methods}

\section{Search strategy}

We followed the PRISMA recommendations for systematic literature analysis [9]. PubMed, the Cochrane Library, EMBASE, and ClinicalTrials.gov were 
searched using the terms "Hepatocellular Carcinoma" or "HCC" or "Hepatoma" or "Liver cancer" and "S-1" in the title or abstract fields. The date of the last search was December 14, 2015. We screened each abstract resulting from these searches for eligibility. We also examined reference lists of each selected original article or conference abstract and the protocol registration system of clinical trials to identify additional articles that might meet our eligibility requirements. Any discrepancies among reviewers were resolved by consensus discussion.

\section{Inclusion criteria}

Studies were included in our review if they evaluated the efficacy and safety of S-1 for treatment of advanced HCC; reported data on at least one of the outcomes of median survival, overall survival (OS), and disease-free survival (DFS) and were published on or before December 21, 2015.

\section{Exclusion criteria}

Exclusion criteria:
1) duplicated records,
2) case report,
3) not advanced hepatocellular carcinoma,
4) letters to the editor,
5) editorials,
6) research protocols,
7) review articles,
8) combination therapy studies,
9) nonhuman studies.

\section{Data abstraction}

The data extracted from each report were: country, control, study type (prospective or retrospective), publication type (original article or conference abstract), number (No.) of patients, percentage of male/female, median age of study participants, Eastern Cooperative Oncology Group (ECOG) performance status (PS) score, percentage of patients with Child-Pugh score $A / B$, percentage of patients with hepatitis $B / C$, percentage of patients with cirrhosis, related indicators of S-1 treatment (Dose of S-1, S-1 administration, one cycle, total cycles, and median cycles), median overall survival (OS), median progression-free survival (PFS), median time to progression (TTP), tumour response (CR, PR SD PD), disease control rate (DCR), and Toxicity (anaemia, thrombocytopaenia, neutropaenia, elevated AST, elevated ALT, fatigue, nausea, diarrhoea, and rash).

\section{Results}

\section{Systematic review flow}

The flow diagram of the systematic review is shown in Fig. 1.

Our initial search yielded 1059 references including 114 from PubMed, 1386 from Embase, five from ClinicalTrials.gov, and four from the Cochrane Library. In the step of "preliminary titles screened", the "search panel" of endnote was used to search in a mass of references with the terms "case", "gastric cancer", "colon cancer", "breast cancer", and "pancreatic cancer" in sequence. Then we deleted 726 unwanted references. In the step of "Full-text articles screened", one article was excluded by reading the

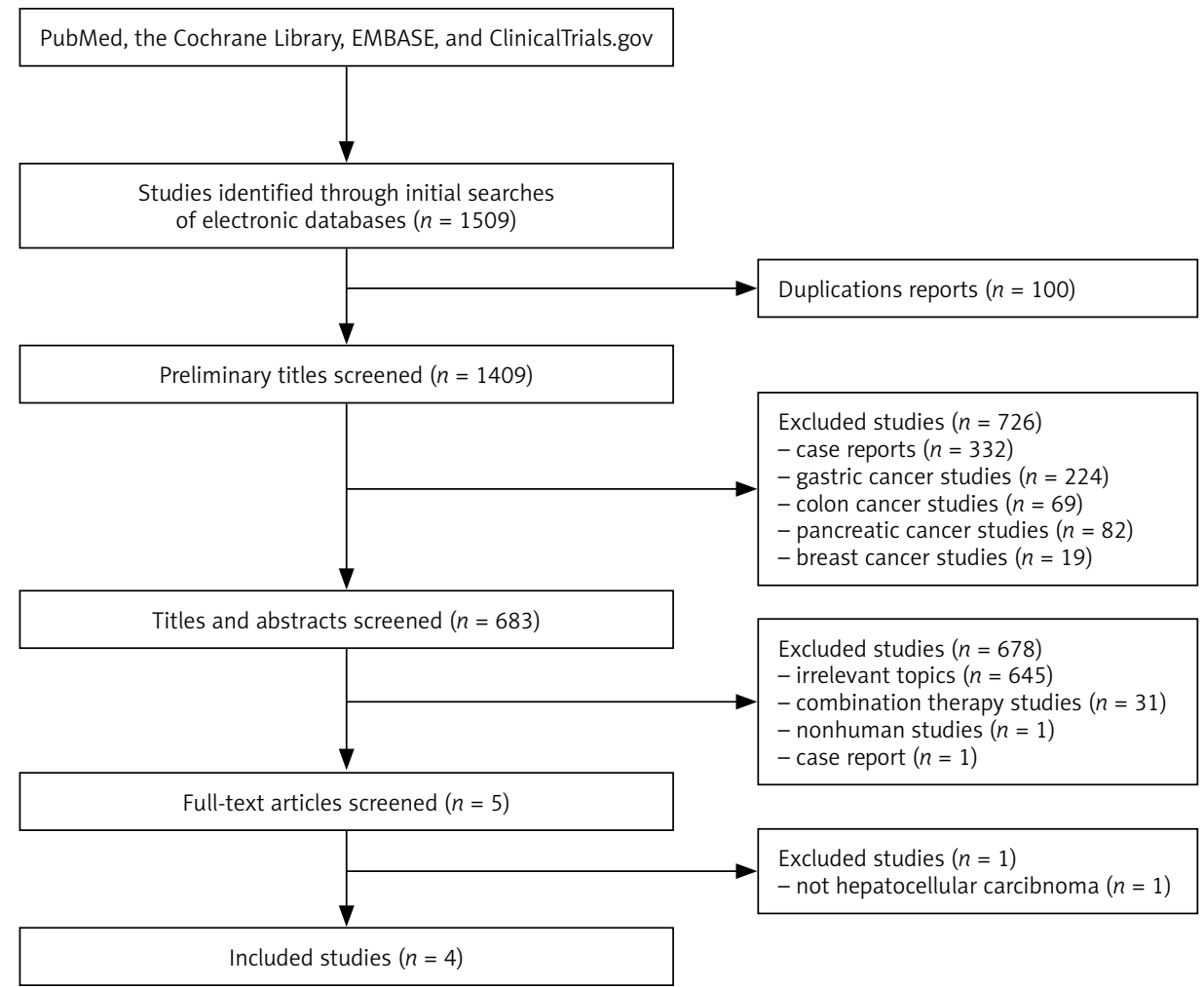

Fig. 1. Flow diagram of studies identified, included, and excluded 
Table 1. Baseline patient demographic and disease characteristics

\begin{tabular}{|c|c|c|c|c|c|c|c|c|c|c|c|}
\hline Study & Country & Control & Study type & $\begin{array}{c}\text { Publication } \\
\text { type }\end{array}$ & $\begin{array}{c}\text { No. of } \\
\text { patients }\end{array}$ & $\begin{array}{l}\text { Male/ } \\
\text { Female } \\
(\%)\end{array}$ & $\begin{array}{l}\text { Median } \\
\text { age } \\
\text { (years) }\end{array}$ & $\begin{array}{c}\text { ECOG PS } \\
\text { score } 0 / 1 \\
(\%)\end{array}$ & $\begin{array}{l}\text { Child- } \\
\text { Pugh A/B } \\
\text { (\%) }\end{array}$ & $\begin{array}{c}\text { Etiology } \\
\text { HBV/HCV } \\
(\%)\end{array}$ & $\begin{array}{c}\text { Cirrhosis } \\
\text { (\%) }\end{array}$ \\
\hline Yu 2015 & China & $\begin{array}{c}\text { best } \\
\text { supportive } \\
\text { care }\end{array}$ & retrospective & $\begin{array}{c}\text { conference } \\
\text { abstract }\end{array}$ & 18 & NA & NA & $91.3 / 8.7$ & NA & NA & NA \\
\hline $\begin{array}{l}\text { Kudo } \\
2015\end{array}$ & Japan & placebo & NA & $\begin{array}{c}\text { conference } \\
\text { abstract }\end{array}$ & 223 & NA & 70 & NA & $81 / N$ & NA & NA \\
\hline $\begin{array}{l}\text { Furuse } \\
2010\end{array}$ & Japan & none & prospective & $\begin{array}{l}\text { original } \\
\text { article }\end{array}$ & 23 & $91.3 / 8.7$ & 68 & $91.3 / 8.7$ & $69.6 / 30.4$ & $13.0 / 60.9$ & NA \\
\hline $\begin{array}{l}\text { Nagata } \\
2007\end{array}$ & Japan & none & retrospective & $\begin{array}{l}\text { original } \\
\text { article }\end{array}$ & 8 & 0/12.0 & 59 & NA & $100 / 0$ & $50.0 / 25.0$ & NA \\
\hline
\end{tabular}

NA - not available; ECOG - Eastern Cooperative Oncology Group; PS - performance status

Table 2. Treatment of S-1

\begin{tabular}{|c|c|c|c|c|c|}
\hline Study & $\begin{array}{l}\text { Dose of } \mathrm{S}-1 \\
\left(\mathrm{mg} / \mathrm{m}^{2} / \text { day }\right)\end{array}$ & $\begin{array}{l}\text { S-1 admini- } \\
\text { stration } \\
\text { (days) }\end{array}$ & $\begin{array}{l}\text { One } \\
\text { cycle } \\
\text { (days) }\end{array}$ & $\begin{array}{c}\text { Total } \\
\text { cycles } \\
\text { (times) }\end{array}$ & $\begin{array}{c}\text { Median } \\
\text { cycles } \\
\text { (times, } \\
\text { range) }\end{array}$ \\
\hline Yu 2015 & 80 & $1-14$ & 21 & 63 & $\begin{array}{c}3.5 \\
(2-7)\end{array}$ \\
\hline $\begin{array}{l}\text { Kudo } \\
2015\end{array}$ & $\begin{array}{l}80,100 \\
\text { and } 120\end{array}$ & $1-28$ & 42 & NA & NA \\
\hline $\begin{array}{l}\text { Furuse } \\
2010\end{array}$ & 80 & $1-28$ & 42 & 85 & NA \\
\hline $\begin{array}{l}\text { Nagata } \\
2007\end{array}$ & 80 & $1-28$ & 42 & 22 & $\begin{array}{l}\text { NA } \\
(1-5)\end{array}$ \\
\hline
\end{tabular}

NA - not available

Table 3. Efficacy evaluation

\begin{tabular}{lccc} 
Study & $\begin{array}{c}\text { Median OS } \\
\text { (months) }\end{array}$ & $\begin{array}{c}\text { Median PFS } \\
\text { (months) }\end{array}$ & $\begin{array}{c}\text { Median TTP } \\
\text { (months) }\end{array}$ \\
\hline Yu 2015 & $15.1^{\mathrm{a}}$ & $\mathrm{NA}$ & $4.7^{\mathrm{a}}$ \\
Kudo 2015 & $11.3^{\mathrm{b}}$ & $2.67^{\mathrm{b}}$ & $\mathrm{NA}$ \\
Furuse 2010 & 16.6 & 3.7 & $\mathrm{NA}$ \\
Nagata 2007 & $8.6^{\mathrm{b}}$ & $2.65^{\mathrm{b}}$ & $\mathrm{NA}$
\end{tabular}

compared to control group, $p<0.05$

${ }^{b}$ days in original divided by 30 , and then got months

NA - not available; OS - overall survival; PFS - progression-free survival; TTP time to tumor progression; $D C R$-disease control rate; $C R$-complete response; $P R$ - partial response; $S D$ - stable disease; $P D$ - progression disease

full text. Its title is "Pharmacokinetic evaluation of novel oral fluorouracil antitumor drug S-1 in Chinese cancer patients". The objects of the study are gastrointestinal cancer, non-small-cell lung cancer, head and neck cancer, unresectable or recurrent breast cancer, and pancreatic cancer, but not HCC [10]. Ultimately, four studies were chosen for review including two original articles and two conference abstracts.

\section{Baseline patient demographic and disease characteristics}

Baseline patient demographic and disease characteristics, which included a total of 272 patients of four studies, are summarised in Table 1. Three studies came from Japan [11-13] and one study from China [14]. There were two original articles [12, 13] and two conference abstracts [11, 14]. Two studies described control groups, one best supportive care (BSC) [14], and one placebo [11]. Three studies described study type, one prospective study [12], and two retrospective studies $[13,14]$. The percentage of male patients ranged from 88 [13] to $91.3 \%$ [12]. Median age ranged from 59 [13] to 70 years [11].

\section{Treatment of S-1}

The relevant treatment data of S-1 can be seen in Table 2. All studies described dose of S-1, days of S-1 administration, and one cycle. $80 \mathrm{mg} / \mathrm{m}^{2} /$ day was the most common dose of S-1. S-1 was administered orally on days 1-28 of a 42-day cycle in three studies [11-13] and days 1-14 of a 21-day cycle in one study [14]. Total cycles ranged from 22 [13] to 85 [12] in three studies. Median cycles were 3.5 (range: 2-7) fully reported in one study [14].

\section{Efficacy evaluation}

Efficacy evaluations of S-1 for treatment of advanced HCC are summarised in Table 3.

Four studies provided precise OS, and Median OS ranged from 8.6 [13] to 16.5 months [12]. In YU's study, OS was 15.1 months in patients treated with S-1, compared with 8.3 months in the BSC group $(p=0.027)$ [14]. Median PFS ranged from 2.65 [13] to 3.7 months [12] in three studies. in one study, median TTP was 4.7 months in the S-1 group compared with 2.3 months in the BSC group ( $p=0.013$ ) [14]. There was not CR in four studies. Three studies in four described DCRs, which ranged from 37.4 [13] to $69.4 \%$ [12].

\section{Toxicity}

Toxicities of S-1 are shown in Table 4. According to the original description, toxicities were acceptable. The incidences of toxicity of more than $50 \%$ were thrombocytopaenia and fatigue in at least two studies. Three studies described numeric toxicities, and one study showed that the main adverse events (AEs) with S-1 were anorexia, fatigue, elevated total bilirubin, and diarrhoea, and most AEs were mild to moderate [11]. One study only reported that the most common grade 3/4 toxicities were thrombocytopaenia (28.1\%), neutropaenia (21.8\%), elevated se- 
Table 4. Toxicity (\%)

\begin{tabular}{|c|c|c|c|c|c|c|c|c|c|}
\hline Study & Anemia & Thrombocytopenia & Neutropenia & $\begin{array}{c}\text { Elevated } \\
\text { AST }\end{array}$ & $\begin{array}{c}\text { Elevated } \\
\text { ALT }\end{array}$ & Fatigue & Nausea & Diarrhea & Rash \\
\hline $\begin{array}{l}\text { Yu } \\
2015\end{array}$ & NA & $\begin{array}{c}28.1 \\
\text { (grade 3/4) }\end{array}$ & $\begin{array}{c}21.8 \\
\text { (grade 3/4) }\end{array}$ & $\begin{array}{c}15.6 \\
\text { (grade 3/4) }\end{array}$ & NA & NA & NA & NA & $\begin{array}{c}9.4 \\
\text { (grade } 3 / 4 \text { ) }\end{array}$ \\
\hline $\begin{array}{l}\text { Kudo } \\
2015\end{array}$ & NA & NA & NA & NA & NA & NA & NA & NA & NA \\
\hline $\begin{array}{l}\text { Furuse } \\
2010\end{array}$ & 82.6 & 78.3 & 73.9 & 33.3 & NA & 82.6 & & 43.5 & 34.8 \\
\hline $\begin{array}{l}\text { Nagata } \\
2007\end{array}$ & 0 & 50 & 25 & 63 & 50 & 50 & 0 & 0 & 0 \\
\hline
\end{tabular}

NA - not available; AST - aspartate aminotransferase; ALT - alanine aminotransferase

rum aspartate aminotransferase levels (15.6\%), and rash $(9.4 \%)[14]$

\section{Discussion}

There is currently little information on S-1 for treatment of HCC. This systematic review showed that S-1 treatment was associated with an interesting OS and a short PFS to advanced HCC. In the four studies, the median PFS ranged from 2.65 to 3.7 months. The smallest median OS was 8.6 months, and three other median OS were more than 11 months. There were two case-controlled studies in four. The study populations were from China and Japan, respectively. In the Chinese study controlled to BSC, S-1 treatment prolonged OS by 6.8 months (from 8.3 to 15.1 months), and the difference was statistically significant ( $p=0.027)$ [14] In the Japanese study controlled to placebo, S-1 treatment failed to prolong OS (337.5 vs. 340.0 days) [11]. The two uncontrolled studies of S-1 described OS as long as 16.6 months, but with no control group the contribution of S-1 to these outcomes is not clear.

To our knowledge, sorafenib is the only systemic therapy approved by the United States Food and Drug Administration (FDA) for the treatment of unresectable HCC. Two phase III, randomised, placebo-controlled clinical trials have explored the efficacy and safety of sorafenib in patients with advanced HCC. In these two trials, sorafenib treatment prolonged OS by 2.3 to 2.8 months (one from 4.2 to 6.5 months [15], and the other from 7.9 to 10.7 months [16]). In addition, many studies using hepatic arterial infusion chemotherapy (HAIC) have been performed in advanced HCC. In these studies, the median OS ranged from 6.9 to 10.2 months [17-20]. Recently, a multicentre, randomised, open-labelled, clinical trial aimed to evaluate the efficacy and safety of cisplatin/5-fluorouracil (5-FU) HAIC (CF-HAIC) vs. adriamycin added to CF-HAIC (ACF-HAIC) in advanced HCC, and showed that the median OS in the ACF-HAIC and CF-HAIC groups were 8.8 months and 11.1 months, respectively. Furthermore, there was a study aimed at comparing the efficacy of HAIC and sorafenib in advanced HCC patients with portal vein tumour thrombosis (PVTT), which showed that the median OS was significantly longer in the HAIC group than in the sorafenib group (7.1 vs. 5.5 months, $p=0.011$ ) [21]. At present, there is no randomised controlled study of S-1 vs. sorafenib or S-1 vs. HAIC reported in the literature. Therefore, it is not known which treatment gives longer OS.
This systematic review showed that S-1 treatment also had a favourable safety profile in this study. The most frequently described toxicities of S-1 were anaemia, thrombocytopaenia, neutropaenia, elevated AST, elevated ALT, elevated serum bilirubin, reduced serum albumin, fatigue, nausea, diarrhoea, stomatitis, pigmentation, hand-foot syndrome, and rash. Most of them were included in this systematic review.

The incidences of toxicity reaction of more than 50\% were thrombocytopaenia and fatigue in at least two studies. S-1 (i.e. tegafur/gimeracil/oteracil potassium, known as Tiji'ao capsule in China) was a novel oral 5-fluoro-2,4 ( $1 \mathrm{~h}, 3 \mathrm{~h}$ ) pyrimidinedione (5-FU) analogue, which contained tegafur and two biochemical modulators for 5-FU. Tegafur was a metabolically activated prodrug of 5-FU, and was effective as adjuvant chemotherapy after TACE [22]. 5-Chloro-2,4-dihydroxypyridine can enhance the pharmacological actions of 5-FU by inhibiting its degradation by dihydropyrimidine dehydrogenase (DPD). Potassium oxonate was localised in the mucosal cells of the gastrointestinal tract after oral administration. By means of suppressing the activation of 5-FU in the gastrointestinal tract, it reduced the incidence of gastrointestinal toxicities [23]. S-1 showed better anti-tumour activity and lower toxicity compared to 5-FU. In all toxicities listed in Table 4, the incidence of fatigue seemed to be the highest. Because of inadequate data from two conference abstracts [11, 14], it was difficult to perform further analysis, but according to the original description, the toxicities were acceptable. Other studies also supported this view. A single-centre study aimed at evaluating the effects of continuing adjuvant S-1 for one year on the prognosis of gastric cancer patients demonstrated that common side effects included diarrhoea, oral ulcers, and skin rash, and grade 3/4 toxicities occurred in $1.9 \%$ and $5.7 \%$ of patients, respectively [24]. In A meta-analysis of S-1 vs. capecitabine for the treatment of gastric cancer, the most frequent toxicities of S-1 included neutropaenia, thrombocytopaenia, nausea, and hand-foot syndrome. Compared with the capecitabine regimen, there were no significant differences. However, hand-foot syndrome at any grade was more frequently noted in the capecitabine group than in the S-1 group [25].

There were some limitations in this systematic review, which should be acknowledged. Firstly, two of the four studies included were case controlled studies while the other two were not. Hence, the evidence from the other 
two studies was not of high quality. Secondly, there might be publication bias in this research area. Taking into consideration the conference abstracts, there were no further detailed descriptions in standard publications. Thirdly, there were clearly a lot of confounding factors (ECOG PS score, age, S-1 administration, and aetiology) that led to analysis and summary difficulties. Fourthly, efficacy evaluation except for OS was not consistent among the different studies, with three studies using PFS while the other was using TTP.

In conclusion, the current evidence from the available clinical studies suggests that S-1 may be an effective and tolerable treatment for advanced HCC. Prospective, randomised, multicentric, controlled trials are warranted to further investigate this treatment option for advanced HCC. In addition, possible combinational therapies could be researched with other locoregional treatments (e.g. chemoembolisation/radioembolisation plus S-1, radiofrequency ablation plus S-1).

The authors declare no conflict of interest.

This work was supported by grants from the Scientific Research and Innovation Foundation of Xinjiang Medical University (No. XJC2013118).

\section{References}

1. Parkin DM, Bray F, Ferlay J, Pisani P. Global cancer statistics, 2002. CA Cancer J Clin 2005; 55: 74-108.

2. Hernandez BY, Green MD, Cassel KD, Pobutsky AM, Vu V, Wilkens LR. Preview of Hawaii Cancer Facts and Figures 2010. Hawaii Med J 2010; 69: 223-4.

3. El-Serag HB, Davila JA, Petersen NJ, McGlynn KA. The continuing increase in the incidence of hepatocellular carcinoma in the United States: an update. Ann Intern Med 2003; 139: 817-23.

4. El-Serag HB. Epidemiology of hepatocellular carcinoma in USA Hepatol Res 2007; 37 Suppl 2: S88-94.

5. Lee JE, Bae SH, Choi JY, Yoon SK, You YK, Lee MA. Epirubicin, cisplatin, 5-FU combination chemotherapy in sorafenib-refractory metastatic hepatocellular carcinoma. World J Gastroenterol 2014; 20: 235-41.

6. Lv Y, Liang R, Hu X, Liu Z, Liao X, Lin Y, et al. Combination of oxaliplatin and S-1 versus sorafenib alone in patients with advanced hepatocellular carcinoma. Pharmazie 2014; 69: 759-63.

7. Kim JJ, Tannock IF. Repopulation of cancer cells during therapy: an important cause of treatment failure. Nat Rev Cancer 2005; 5: $516-25$

8. Shao YY, Huang CC, Liang PC, Lin ZZ. Hepatic arterial infusion of chemotherapy for advanced hepatocellular carcinoma. Asia Pac J Clin Oncol 2010; 6: 80-8

9. Moher D, Liberati A, Tetzlaff J, Altman DG, Group P. Preferred reporting items for systematic reviews and meta-analyses: the PRISMA statement. PLoS One 2009; 6: e1000097.

10. Zhuang ZX, Zhu H, Wang J, Zhu MG, Wang H, Pu WY, et al. Pharmacokinetic evaluation of novel oral fluorouracil antitumor drug S-1 in Chinese cancer patients. Acta Pharmacol Sin 2013; 34: 570-80.

11. Kudo M, Moriguchi M, Numata K, Hidaka H, Tanaka H, Ikeda M, et al. A randomized, double-blind, placebo-controlled phase III study of S-1 in patients with sorafenib-refractory advanced hepatocellular carcinoma (S-CUBE). J Clin Oncol 2015; 33 (suppl; abstr 4018).

12. Furuse J, Okusaka T, Kaneko S, Kudo M, Nakachi K, Ueno H, et al. Phase I/II study of the pharmacokinetics, safety and efficacy of S-1 in patients with advanced hepatocellular carcinoma. Cancer Sci 2010; 101: 2606-11.

13. Nagata H, Hatano E, Asechi H, Narita M, Yanagida A, Yasuchika K, et al. Retrospective analysis of clinical results in eight patients with advanced hepatocellular carcinoma with lung metastases treated by TS-1. Gan To Kagaku Ryoho 2007; 34: 233-5.

14. Yu P. Comparative efficacy of S-1 versus best supportive care in advanced hepatocellular carcinoma. J Clin Oncol 2015; 33 (suppl).

15. Llovet JM, Ricci S, Mazzaferro V, Hilgard P, Gane E, Blanc JF, et al. Sorafenib in advanced hepatocellular carcinoma. N Engl J Med 2008; 359: 378-90.

16. Cheng AL, Kang YK, Chen Z, Tsao CJ, Qin S, Kim JS, et al. Efficacy and safety of sorafenib in patients in the Asia-Pacific region with advanced hepatocellular carcinoma: a phase III randomised, double-blind, placebo-controlled trial. Lancet Oncol 2009; 10: 25-34.

17. Song do S, Bae SH, Song MJ, Lee SW, Kim HY, Lee YJ, et al. Hepatic arterial infusion chemotherapy in hepatocellular carcinoma with portal vein tumor thrombosis. World I Gastroenterol 2013; 19: 4679-88

18. Obi S, Yoshida H, Toune R, Unuma T, Kanda M, Sato S, et al. Com bination therapy of intraarterial 5 -fluorouracil and systemic interferon-alpha for advanced hepatocellular carcinoma with portal venous invasion. Cancer 2006; 106: 1990-7.

19. Lai YC, Shih CY, Jeng CM, Yang SS, Hu JT, Sung YC, et al. Hepatic arterial infusion chemotherapy for hepatocellular carcinoma with portal vein tumor thrombosis. World I Gastroenterol 2003; 9: 2666-70.

20. Ando E, Tanaka M, Yamashita F, Kuromatsu R, Yutani S, Fukumori K, et al. Hepatic arterial infusion chemotherapy for advanced hepatocellular carcinoma with portal vein tumor thrombosis: analysis of 48 cases. Cancer 2002; 95: 588-95.

21. Song do S, Song MJ, Bae SH, Chung WJ, Jang JY, Kim YS, et al. A comparative study between sorafenib and hepatic arterial infusion chemotherapy for advanced hepatocellular carcinoma with portal vein tumor thrombosis. J Gastroenterol 2015; 50: 445-54.

22. Ueda H, Tanaka H, Kida Y, Fukuchi H, Ichinose M. Adjuvant chemotherapy with tegafur/uracil administration after transcatheter arterial chemoembolization for advanced hepatocellular carcinoma. Oncol Rep 2008; 19: 1355-61.

23. Shirasaka T. Development history and concept of an oral anticancer agent S-1 (TS-1巴): its clinical usefulness and future vistas. Jpn J Clin Oncol 2009; 39: 2-15.

24. Eun H, Hur H, Byun CS, Son SY, Han SU, Cho YK. Effects of continuing adjuvant S-1 for 1 year on the prognosis of gastric cancer patients: results from a prospective single center study. J Gastric Cancer 2015; 15: 113-20.

25. He AB, Peng XL, Song J, Zhang JX, Dong WG, Luo RF, et al. Efficacy of S-1 vs capecitabine for the treatment of gastric cancer: a meta-analysis. World J Gastroenterol 2015; 21: 4358-64.

\section{Address for correspondence}

\section{Xi-wen Fan}

Department of Intervention Radiology

The Affiliated Tumour Hospital of Xinjiang Medical University

789 Suzhou East Road

Urumqi 830011, Xinjiang, People's Republic of China

e-mail: yishijiusheng@126.com

Submitted: 19.03 .2016

Accepted: $\quad 16.11 .2016$ 